\title{
Fatty acid composition and fat content in milk from cows grazing in the Alpine region
}

\section{Gabriella Roda, Stefano Fialà, Michela Vittorini \& Francesco Secundo}

European Food Research and Technology

Zeitschrift für Lebensmittel-

Untersuchung und -Forschung A

ISSN 1438-2377

Eur Food Res Technol

DOI 10.1007/s00217-015-2473-3

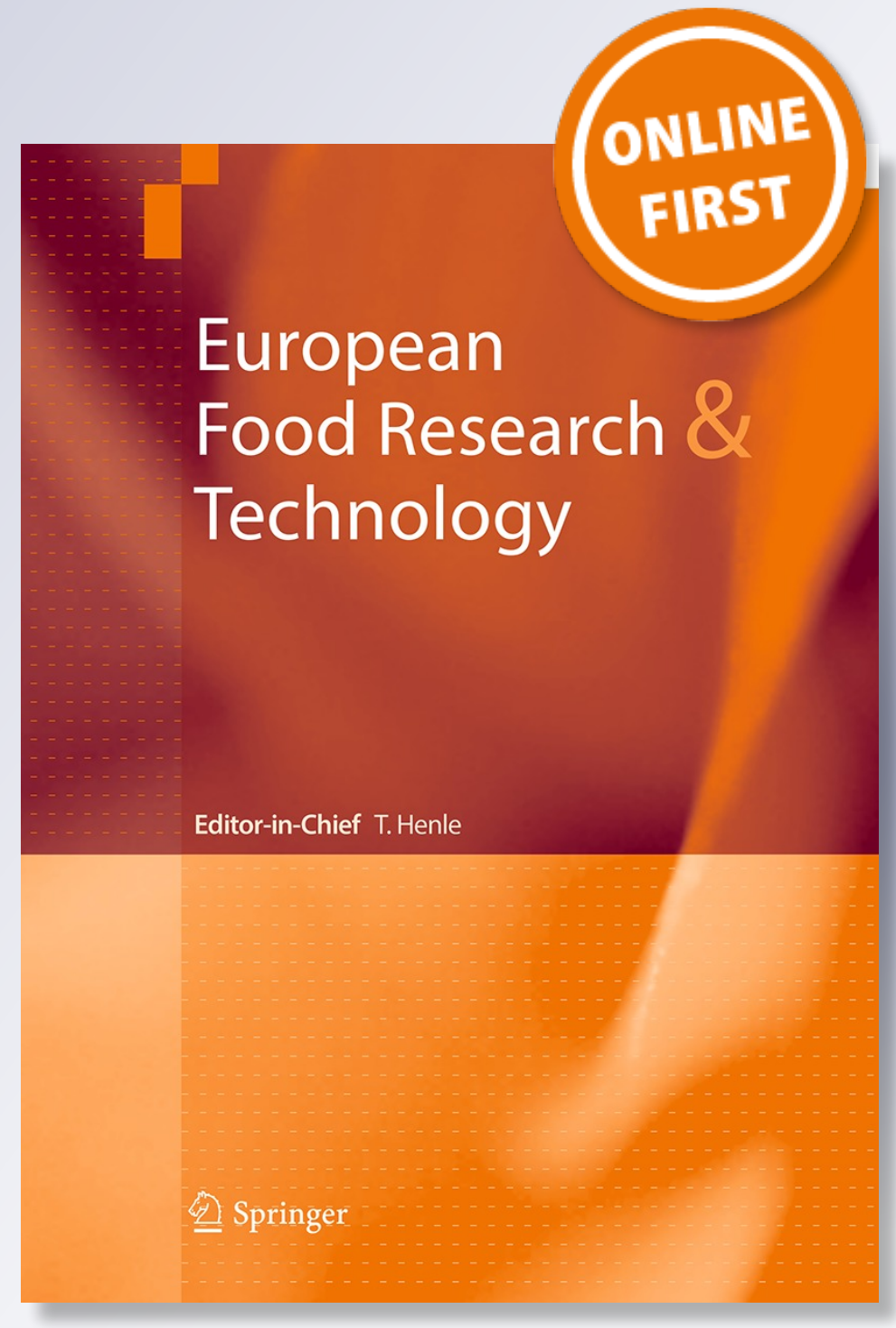

黛 Springer 
Your article is protected by copyright and all rights are held exclusively by SpringerVerlag Berlin Heidelberg. This e-offprint is for personal use only and shall not be selfarchived in electronic repositories. If you wish to self-archive your article, please use the accepted manuscript version for posting on your own website. You may further deposit the accepted manuscript version in any repository, provided it is only made publicly available 12 months after official publication or later and provided acknowledgement is given to the original source of publication and a link is inserted to the published article on Springer's website. The link must be accompanied by the following text: "The final publication is available at link.springer.com". 


\title{
Fatty acid composition and fat content in milk from cows grazing in the Alpine region
}

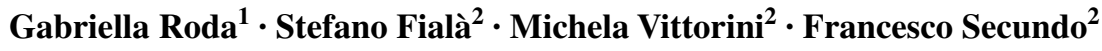

Received: 27 February 2015 / Revised: 1 May 2015 / Accepted: 9 May 2015

(C) Springer-Verlag Berlin Heidelberg 2015

\begin{abstract}
The variation in the fat profile of pooled milk from cows grazing in pastures in June and July at 400 $700 \mathrm{~m}$ and at $1400-2250 \mathrm{~m}$ of altitude was evaluated by gas chromatography and compared with that from cows stalled in barns and fed with a diet without fresh grass. The ratios unsaturated/saturated fatty acid in milk samples were 1.33, 1.71 and 1.69 in June and 1.21, 1.69 and 1.84 in July for cows fed with prepared diet, grazing at 400-700 m or grazing at 1400-2250 m, respectively. Analogously, the ratios (oleic plus stearic acid)/palmitic acid were, for the same group of cows, $0.59,0.72$ and 0.78 in June and $0.56,0.73$ and 0.81 in July. In milk from pastured cows, the percentage of oleic, vaccenic, rumenic and $\alpha$-linolenic acids increased as a function of the altitude; instead, that of linoleic acid and of cis-12-octadecenoic acid decreased. The yield of fat was always highest in milk from 1400 to $2250 \mathrm{~m}$ of altitude (up to $3.6 \mathrm{~g}$ per $100 \mathrm{~mL}$ ). For the milk collected in July at $1400-2250 \mathrm{~m}$ of altitude, it was observed a decrease in the percentage of decanoic (capric) and dodecanoic acids and an increase in pentadecanoic, stearic, arachidic and docosanoic (behenic) acids. Possible reasons for the differences observed in the milk samples were discussed.
\end{abstract}

Keywords Linoleic acid - Linolenic acid · Vaccenic acid . Rumenic acid $\cdot$ Cow metabolism $\cdot$ Alps

Francesco Secundo

francesco.secundo@icrm.cnr.it

1 Dipartimento di Scienze Farmaceutiche, Università degli Studi di Milano, Via Mangiagalli 25, 20133 Milan, Italy

2 Istituto di Chimica del Riconoscimento Molecolare, CNR, Via M. Bianco 9, 20131 Milan, Italy

\section{Introduction}

Cow milk fat content and its fatty acid (FA) profile depend on numerous factors $[1,2]$. They might vary because of incomplete or irregular milking, cow age (fat content increases with aging until a maximum and then it decreases), climatic conditions (dry period and temperature) [3], altitude [4] and lactation period [5] (it is lower in the first quarter after delivery and increases during lactation). Additionally, the composition of diet also influences the milk lipolytic system modifying the butyric acid and short-chain FA formation and the sensorial quality of milk during the lipolysis [6, 7]. Dietary strategy and role of forage in the diet play a crucial role for modification of milk fat content and FA composition [8-14].

Because of the potential impact on human health, FA consumption with diet has been widely studied. Milk and milk derivatives are important sources of beneficial monounsaturated FA (MUFA) and polyunsaturated FA (PUFA) [15-19]. In particular, linoleic acid (cis-9,cis-12-octadecadienoic acid), $\alpha$-linolenic acid (cis-9,cis-12,cis-15-octadecatrienoic acid) and their positional and geometric isomers are the main constituents of PUFA. Linoleic and $\alpha$-linolenic acids are the most abundant octadecadienoic and octadecatrienoic FA isomers in plants and seeds reaching concentrations as high as $50-75 \%$ of the total lipid fraction in forage [20]. PUFA has been shown to have anticarcinogenic and antiatherogenic action [21-24], but usually the human consumption of these beneficial FA is below the dose that could be effective for reducing tumor incidence. Furthermore, the relatively high consumption of saturated fatty acids (SFA), in particular myristic (14:0) and palmitic (16:0) acids, has been associated with human cardiovascular health problems [25]. Therefore, the possibility 
to increase the relative percentage of MUFA and PUFA in milk might be useful for its nutritive and healthy properties.

In the present study, the relative fraction of FA in pooled milk obtained from dairy cows grazing in pastures located in the Alps of Aosta Valley region at different altitude (400-700 and 1400-2250 m) and in two different summer months (June and July) is compared with that measured in milk samples from cows stalled in barns and fed with a prepared diet.

\section{Materials and methods}

\section{Sampling}

Milk from Alpine meadows in Aosta Valley region was collected at two different altitude ranges (400-700 and $1400-2250 \mathrm{~m}$ ) in different farms whose cows belonged to the races of Fresian and Bruna Alpina. Milk samples were withdrawn from pooled milk of ten farms (per each range of altitude considered) in June and July with an intercurring period of time of 1 month between each sampling. In all cases, the samples of milk were frozen at $-20{ }^{\circ} \mathrm{C}$ just after collection and preserved at this temperature until fat extraction.

To better distinguish the peculiarities of fat profile in milk coming from the Alpine region, analytical data were compared with those obtained from bulk milk of cows from five different farms located in Po River basin and fed with a usual prepared diet. This latter consisted in different percentages of corn silage (48-57\%), corn flour (6.3-12.5\%), barley $(0-3.8 \%)$, commercial core $(9.8-14.7 \%)$, hay of Medicago sativa (0-22.5\%), hay of Gramineae (0-5.3\%), hay of Lolium (0-1.9\%), cotton seeds (3.2-5.3\%), soy flour extracted $(0-3.5 \%)$, Lolium silage $(0-1.9 \%)$ and silage of grass from stable meadow (0-10.7\%).

\section{Chemicals}

All FA methyl esters (FAME) were obtained from SigmaAldrich (Milan, Italy) except the methyl ester of cis-9, trans-11-octadecadienoic acid (conjugated, rumenic acid) and of trans-11-octadecenoic acid (vaccenic acid) that were purchased from Nu-Check, USA. All the other reagents and solvents were of analytical grade.

\section{Fat extraction}

Lipids were extracted according to official protocol ISO14156-IDF172. Briefly, all milk samples were homogenized in a water bath at $35^{\circ} \mathrm{C}$, mixed by repeated inversion and then quickly cooled to $20{ }^{\circ} \mathrm{C}$. Milk samples $(20 \mathrm{~mL})$ were mixed with $16 \mathrm{~mL}$ of ethanol, $4 \mathrm{~mL}$ of ammonia solution (30\%) and $20 \mathrm{~mL}$ of diethyl ether in a separating funnel, and the solutions vigorously shaken for $1 \mathrm{~min}$. Then $20 \mathrm{~mL}$ of petroleum ether was added, and the samples were mixed carefully. After phase separation, the aqueous layers were discarded. The organic phases were treated twice with $20 \mathrm{~mL}$ of sodium sulfate solution (10\% in water) and then transferred into glass tubes. The samples were dried over anhydrous sodium sulfate and evaporated under reduced pressure. Recovery was evaluated by adding $40 \mu \mathrm{L}$ of dodecane as internal standard in $20 \mathrm{~mL}$ of milk. The fat obtained was weighted and stored at $-20^{\circ} \mathrm{C}$.

\section{FA methyl ester preparations}

FAME were prepared according to official protocol ISO15884-IDF182. Briefly, $0.2 \mathrm{~mL}$ of potassium hydroxide methanolic solution $(2 \mathrm{M})$ was added to $5 \mathrm{~mL}$ of a fat extract solution $(20 \mathrm{mg} / \mathrm{mL})$ in petroleum ether. The solutions were vigorously mixed with the vortex mixer for $1 \mathrm{~min}$, and after an additional reaction time of $5 \mathrm{~min}$, an excess of sodium hydrogen sulfate was added. The samples were shaken again, centrifuged and after decantation were used for GC analyses.

\section{Gas-liquid chromatography}

Analyses of FAME were carried out by using an Agilent Technologies Inc. 6850 gas chromatograph (Milan, Italy), equipped with a split-splitless injector, a FID detector and a column MegaWax $25 \mathrm{~m}$ long, ID $0.32 \mathrm{~mm}$, film thickness $0.25 \mu \mathrm{m}$ (Mega s.n.c, Legnano, Italy). Analytical conditions are as follows: oven temperature from $40{ }^{\circ} \mathrm{C}$ (initial time $1 \mathrm{~min})$ to $150{ }^{\circ} \mathrm{C}\left(10{ }^{\circ} \mathrm{C} / \mathrm{min}\right)$, to $250{ }^{\circ} \mathrm{C}\left(5^{\circ} \mathrm{C} / \mathrm{min}\right)$ (final time $5 \mathrm{~min}$ ); $\mathrm{H}_{2}$ as carrier gas (flow rate $1.2 \mathrm{~mL} / \mathrm{min}$ ); injection temperature $300{ }^{\circ} \mathrm{C}$; volume injected $1 \mu \mathrm{L}$ and split ratio 1:50. Peak areas were determined by means of Software Agilent G2070 ChemStation.

\section{Statistical analysis}

Analyses were carried out in triplicate and were expressed as mean \pm standard deviation (SD). Statistical differences of data were examined by using the Student's $t$ test, calculated by Microsoft Excel software.

\section{Results}

Milk extracted fat is a parameter that emphasizes the differences between the milk samples. We observed that in June and in July fat content increased with the pasture altitude. Furthermore, in June and July milk produced from cows fed with a prepared diet had a slightly lower fat content 
compared with that obtained from grazing cows $(P<0.05)$. However, in July fat milk content was more dependent on the altitude being at $1400-2250 \mathrm{~m}$ about 10 and $20 \%$ higher $(P \leq 0.01)$ than that obtained at $400-700 \mathrm{~m}$ and from cows fed with a prepared diet, respectively (Table 1).

By GC, we obtained a satisfactory separation and quantification of the most important saturated and unsaturated FA (data not shown). In particular, octadecenoic acids as oleic acid (cis-9-octadecenoic acid), vaccenic acid, cis12-octadecenoic acid, octadecadienoic acids, linoleic and rumenic acids, which are nutritionally desirable functional fat of milk, were detected [26, 27]. Furthermore, a baseline separated peak, assigned to methyl $\alpha$-linolenate on the basis of a standard, was also monitored.

Figure 1 shows the variation in FA in milk obtained from cows fed with prepared diet, grazing at 400-700 m or milk from 1440 to $2250 \mathrm{~m}$ in June and in July. Concerning unsaturated FA, the percentage of oleic acid, vaccenic acid, rumenic acid and $\alpha$-linolenic acid was significantly lower $(P<0.01)$ for the cows fed with a standard diet than for the cows grazing at $400-700 \mathrm{~m}$ or at 1440 $2250 \mathrm{~m}$. These latter two groups of cows also showed a concomitant decrease in the relative percentage of linoleic (18:2, cis-9,cis-12) and cis-12-octadecenoic acids $(P<0.01$ in June and $P<0.1$ in July). Interestingly, the percentage of $\alpha$-linolenic acid increased as a function of the altitude and independently of the period, being 1.5 and $0.87 \%$ in June and 1.1 and $1.5 \%$ in July in the milk obtained from cows grazing at 1440-2250 $\mathrm{m}$ and 400$700 \mathrm{~m}$, respectively. Analogously, also vaccenic acid had a similar trend, even though only in July, and it resulted 5.0 and $4.0 \%$ in the milk from cows at $1440-2250 \mathrm{~m}$ and at $400-700 \mathrm{~m}$, respectively.

With regard to saturated FA, the samples from pastured cows had a significant lower content of lauric (12:0), miristic (14:0) and palmitic acids $(16: 0)(P<0.01$ in all cases $)$ with respect to milk from cows fed with a standard diet. Arachidic acid (20:0) and behenic acid (22:0) increased both as a function of the altitude $(P<0.01)$. No significant variation was observed for stearic acid (18:0) between the various groups. Instead, only in the case of milk obtained

Table 1 Fat content in milk samples harvested at different altitudes ${ }^{\mathrm{a}}$

\begin{tabular}{llll}
\hline Month & Cow fed with prepared diet & $400-700 \mathrm{~m}^{\mathrm{c}}$ & $1400-2250 \mathrm{~m}^{\mathrm{c}}$ \\
\hline June & $2.9 \pm 0.2$ & $3.2 \pm 0.3$ & $3.3 \pm 0.4$ \\
July & $2.8 \pm 0.1$ & $3.0 \pm 0.3$ & $3.6 \pm 0.3$ \\
\hline
\end{tabular}

${ }^{a}$ Values are reported as $\mathrm{g}$ of fat per $100 \mathrm{~mL}$ of milk \pm s.d. (means obtained from 10 different samples assayed in duplicate). Percent of recovery was $94 \pm 5$

b See "Materials and methods" for the composition of prepared diet

c Range of altitude where milk samples were harvested
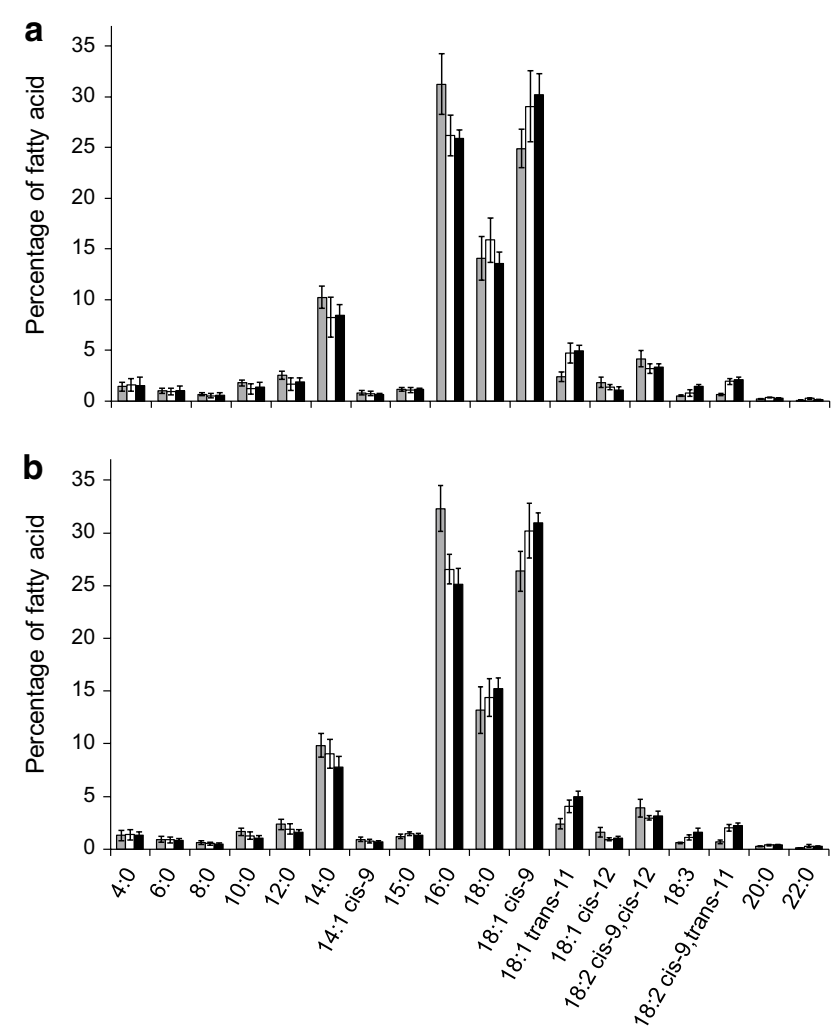

Fig. 1 Fatty acid composition of milk from cows fed with standard diet (gray), Alpine pasture in Aosta Valley region at altitude range of 400-700 m (white) and at 1400-2250 m (black) collected in June (a) and in July (b). (Mean of 10 determinations; bars correspond to the s.d.)

Table 2 Percentages of saturated fatty acids in milk from cows grazing at $1400-2200 \mathrm{~m}$ in June and July ${ }^{\mathrm{a}}$

\begin{tabular}{lccr}
\hline Fatty acid & June $(\%)$ & July $(\%)$ & $P$ value \\
\hline Capric & $1.42 \pm 0.43$ & $1.05 \pm 0.24$ & 0.03 \\
Lauric & $1.91 \pm 0.4$ & $1.57 \pm 0.3$ & 0.05 \\
Pentadecanoic & $1.20 \pm 0.09$ & $1.34 \pm 0.18$ & $<0.01$ \\
Stearic & $13.61 \pm 1.1$ & $15.21 \pm 1.01$ & $<0.01$ \\
Arachidic & $0.31 \pm 0.03$ & $0.40 \pm 0.05$ & $<0.01$ \\
Behenic & $0.18 \pm 0.03$ & $0.26 \pm 0.07$ & $<0.01$ \\
\hline
\end{tabular}

a Only the fatty acids whose variation had a statistical $P$ value $\leq 0.05$ were reported

from cows at $1440-2250 \mathrm{~m}$ a change in some saturated fatty acid between June and July was observed, as shown in Table 2. In particular, a variation in shorter FA as capric (10:0) and lauric (12:0) acids and a concomitant increase in relatively longer chain acids as pentadecanoic, stearic, arachidic and behenic acids can be observed.

The ratios reported in Fig. 2 emphasize some of the differences above discussed (see legend for details). 

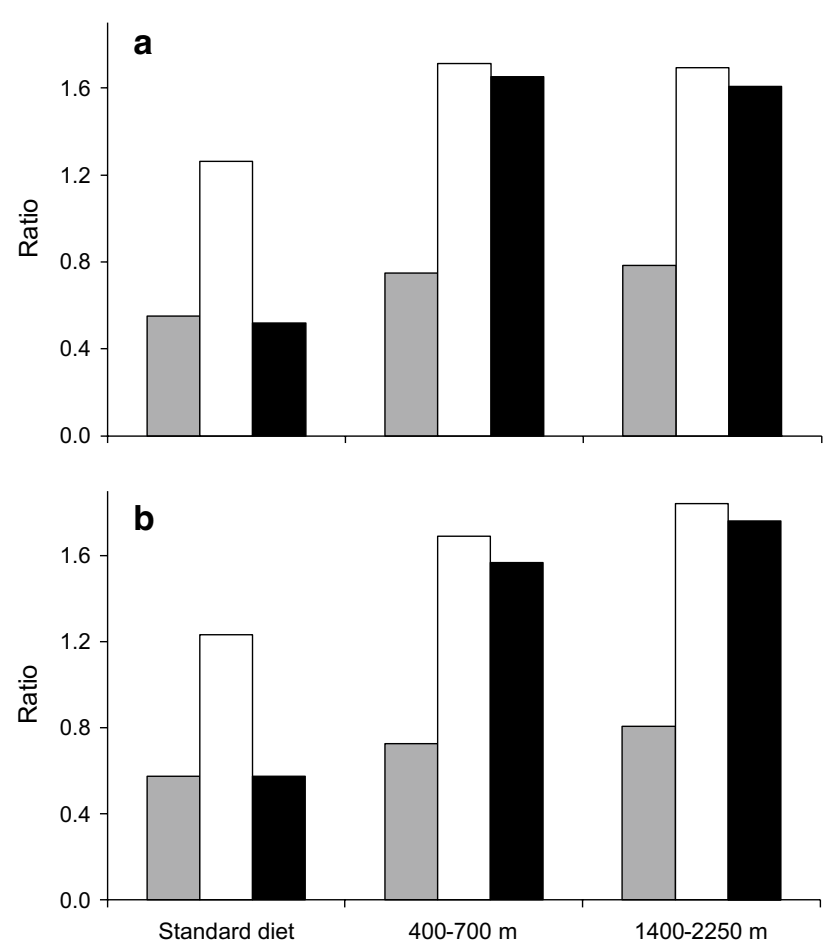

Fig. 2 Ratios (1) unsaturated/saturated FA (gray), (2) (stearic acid + oleic acid)/(palmitic acid) (white) and (3) (rumenic acid + vaccenic acid)/(linoleic acid + cis-12-octadecenoic acid) (black) for the milk samples obtained in June (a) or July (b) from cows fed with standard diet or pastured at the altitude of 400-700 or 1400-2250 m. Ratios (1) and (2) are very sensitive to variations in cow diet, and their increase is usually a desired property for milk quality improvement. Ratio (3) aims at evaluating cow metabolism with regard to biohydrogenation activity in the rumen and/or of $\Delta-9$ desaturase activity in the epithelium of the mammary gland

\section{Discussion}

The enhancement of the levels of MUFA and PUFA is widely considered as a beneficial nutritional characteristic of food in general. The present study showed that milk obtained from cows grazing at high altitude has a fat profile with a higher content of FA as oleic acid, vaccenic acid, rumenic acid and $\alpha$-linolenic acid, which are considered to improve the nutritional properties of milk and also a higher (stearic acid + oleic acid)/(palmitic acid) ratio (Fig. 2) [1, 28-30].

The routes of digestion and metabolism of dietary fatty acids in ruminant were exhaustively described and reviewed by Chilliard et al. [10], and it has been proved by numerous authors that the amount and FA profile in milk depend on the diet of the ruminant [9]. Several research groups reported a higher level of conjugated linoleic acid (CLA) in milk of cows, goats or ewes grazing fresh herb than in the milk from animals fed with dried herbage $[11,31]$. In the present study, we observed that milk obtained from cows grazing in the Alpine region (pasture-fed cows) shows an increased percentage of long-chain saturated (longer than palmitic acids) and unsaturated FAs at the expense of shortand medium-chain (shorter than stearic acid) saturated FA. On the other hand, beyond a comparison of FA composition and fat content of bulk milk obtained from cows pasturing at different altitude in the Alpine region we implicitly compared the influence of supplement feeding versus pasture feeding. Therefore, in agreement with the literature [10, 32-34], it might be suggested that the increase in the unsaturated/saturated FA ratio and the differences in the fatty acid profile observed for the milk from cows grazing at different altitude (Fig. 2) mainly arises from the fresh grass or from the ripeness stage of the grass itself. In fact, the availability of sprouts of grass for a longer period of time, at 1400-2250 m compared with those at 400-700 m or with the standard diet, could also be a reason for the observed differences. Unfortunately, because of the numerous factors that contribute to determine the fat profile of milk (e.g., cow age, breed, kind of grass, etc.), it was not possible a punctual comparison with previous studies and we could not highlight if, beside pasture feeding, other facts due to the altitude (microflora, UV radiation, grass composition) could contribute to the characteristic FA profile for the milk from the Alpine region. To this end, it is worth pointing out that in a recent study carried out by Coppa et al. [35] milk FA composition was not able to authenticate reliably the altitude origin of milk (only $73.8 \%$ of samples correctly classified). In another study, the fraction of omega-3 FA and CLA in milk from cows fed with a continuous grazing on short grass system resulted higher than that obtained from the Austrian Alpine region, and no clear differences were observed for the omega-6 FA [36].

There is still an open debate about the effects of FA on cardiovascular diseases; thus, it is difficult to establish whether these FA might improve dairy product properties [37]. However, unsaturated trans FA as vaccenic and rumenic acids also increase with the altitude. Rumenic acid is the primary octadecadienoic acid isomer (cis-9, trans11-octadecadienoic acid), which accounts for more than $82 \%$ of the total in dairy products [27]. Rumenic acid in milk is mainly formed from linoleic acid, which is transformed in the rumen forming vaccenic acid (trans-11-octadecenoic acid) by means of Butyrivibrio fibrisolves (biohydrogenation). Vaccenic acid can pass into milk directly or after transformation to rumenic acid by the action of $\Delta-9$ desaturase in the epithelium of the mammary gland [10]. This metabolism could be accelerated by a higher amount of fresh grass in the diet. Buccioni et al. [38], by incubating in vitro rumen fluid acid, have found that the biohydrogenation of unsaturated FA was slower with dried herbage than with green herbage. However, because of the differences observed for milk obtained at 1400-2250 m compared with that at 400-700 m, the rumen microflora or secondary 
metabolites of plants which are due to the peculiar conditions found at higher altitude might play an important role [4].

Contrarily to our results, Couvreur et al. [34] showed a linear decrease in milk fat content increasing the proportion of fresh grass in the diet of cows. Therefore, on the basis of this latter indication, it can be suggested that the higher yield of fat in milk from 1400 to $2250 \mathrm{~m}$ (Table 1) is due to a more intense metabolism and lipid intake at this altitude.

In conclusion, the higher level of unsaturated FA and in particular of oleic acid, $\alpha$-linolenic acid and trans FA (vaccenic and rumenic acids) might arise from the fresh grass in the cow diet. Nevertheless, we obtained indications that peculiar conditions present at higher altitude could also be crucial to favor the enhancement of trans FA. Through the present study, we also achieved FA profiles that could be useful to enlarge the available data that characterize the milk from Alpine region, providing parameters for the traceability systems along the whole chain of milk production.

Acknowledgments The authors are grateful to Ministero delle Politiche Agricole Alimentari e Forestali, Project IDENTILAT D.M.304/7303/05 (12/10/2005) that financially supported this publication.

\section{Conflict of interest None.}

Compliance with Ethics requirements This article does not contain any studies with human or animal subjects.

\section{References}

1. Grummer RR (1991) Effect of feed on the composition of milk fat. J Dairy Sci 74:3244-3257

2. Jenkins TC, McGuire MA (2006) Major advances in nutrition: impact on milk composition. J Dairy Sci 89:1302-1310

3. Watters RD, Guenther JN, Brickner AE, Rastani RR, Crump PM, Clark PW, Grummer RR (2008) Effects of dry period length on milk production and health of dairy cattle. J Dairy Sci 91:2595-2603

4. Leiber F, Kreuzer M, Nigg D, Wettstein H, Richard M, Scheeder L (2005) A study on the causes for the elevated n-3 fatty acids in cows' milk of Alpine origin. Lipids 40:191-202

5. Palmquist DL, Beaulieu AD, Barbano DM (1993) Feed and animal factors influencing milk fat composition. J Dairy Sci 76:1753-1771

6. Chilliard Y, Ferlay A, Rouel J, Lamberet G (2003) A review of nutritional and physiological factors affecting goat milk lipid synthesis and lipolysis. J Dairy Sci 86:1751-1770

7. Ferlay A, Martin B, Pradel P, Coulon JB, Chilliard Y (2006) Influence of grass-based diets on milk fatty acid composition and milk lipolytic system in Tarentaise and Montbeliarde cow breeds. J Dairy Sci 89:4026-4041

8. Lock AL, Bauman DE (2004) Modifying milk fat composition of dairy cows to enhance fatty acids beneficial to human health. Lipids 39:1197-1206
9. Palmquist DL, Stelwagen K, Robinson PH (2006) Modifying milk composition to increase use of dairy products in healthy diets. Anim Feed Sci Technol 131:149-153

10. Chilliard Y, Glasser F, Ferlay A, Bernard L, Rouel J, Doreau MD (2007) Rumen biohydrogenation and nutritional quality of cow and goat milk fat. Eur J Lipid Sci Technol 109:828-855

11. Tyagi AK, Kewalramani N, Dhiman TR, Kaur H, Singhal KK, Kanwajia SK (2007) Enhancement of the conjugated linoleic acid content of buffalo milk and milk products through green fodder feeding. Anim Feed Sci Technol 133:351-358

12. Bu DP, Wang JQ, Dhiman TR, Liu SJ (2007) Effectiveness of oils rich in linoleic and linolenic acids to enhance conjugated linoleic acid in milk from dairy cows. J Dairy Sci 90:998-1007

13. Vanhatalo A, Kuoppala K, Toivonen V, Shingfield KJ (2007) Effects of forage species and stage of maturity on bovine milk fatty acid composition. Eur J Lipid Sci Technol 109:856-867

14. Flowers G, Ibrahim SA, AbuGhazaleh AA (2008) Milk fatty acid composition of grazing dairy cows when supplemented with linseed oil. J Dairy Sci 91:722-730

15. Dewhurst RJ, Shingfield KJ, Lee MRF, Scollan ND (2006) Increasing the concentrations of beneficial polyunsaturated fatty acids in milk produced by dairy cows in high-forage systems. Anim Feed Sci Technol 131:168-206

16. Retelny VS, Neuendorf A, Roth JL (2008) Nutrition protocols for the prevention of cardiovascular disease. Nutr Clin Pract 23:468-476

17. Moghadasian MH (2008) Advances in dietary enrichment with n-3 fatty acids. Crit Rev Food Sci Nutr 48:402-410

18. Mills S, Ross RP, Hill C, Fitzgerald GF, Stanton C (2011) Milk intelligence: mining milk for bioactive substances associated with human health. Int Dairy J 21:377-401

19. Lamarche B, Couture P (2015) Dietary fatty acids, dietary patterns, and lipoprotein metabolism. Curr Opin Lipidol 26:42-47

20. Hawke JC (1973) In: Butler GW, Bailey RW (eds) Chemistry and biochemistry of herbage. Academic Press, London

21. Dhiman TR, Anand GR, Satter LD, Pariza MW (1999) Conjugated linoleic acid content of milk from cows fed different diets. J Dairy Sci 82:2146-2156

22. Pariza MW, Park Y, Cook ME (2001) The biologically active isomers of conjugated linoleic acid. Prog Lipid Res 40:283-298

23. Lichtenstein AH (2006) Thematic review series: patient-oriented research. Dietary fat, carbohydrate, and protein: effects on plasma lipoprotein patterns. J Lipid Res 47:1661-1667

24. Liu J, Ma DWL (2014) The role of n-3 polyunsaturated fatty acids in the prevention and treatment of breast cancer. Nutrients 6:5184-5223

25. Zock PL (2006) Health problem associated with saturated and trans fatty acid intake. In: Williams C, Buttriss J (ed) From improving the fat content of foods 3-24

26. Stergiadis S, Leifert C, Seal CJ, Eyre MD, Nielsen JH, Larsen MK, Slots T, Steinshamn H, Butler G (2012) Effect of feeding intensity and milking system on nutritionally relevant milk components in dairy farming systems in the north east of England. J Agric Food Chem 60:7270-7281

27. Borsonelo EC, Galduroz JCF (2008) The role of polyunsaturated fatty acids (PUFAs) in development, aging and substance abuse disorders: review and propositions. Prostaglandins Leukot Essent Fatty Acids 78:237-245

28. Ohlsson L (2010) Dairy products and plasma cholesterol levels. Food Nutr Res 54:1-9

29. French MA, Sundram K, Clandinin MT (2002) Cholesterolaemic effect of palmitic acid in relation to other dietary fatty acids. Asia Pac J Clin Nutr 7:401-407

30. Huth PJ, Park KM (2012) Influence of dairy product and milk fat consumption on cardiovascular disease risk: a review of the evidence. Adv Nutr 3:266-285 
31. Kelly ML, Kolver ES, Bauman DE, Van Amburgh ME, Muller LD (1998) Effect of intake of pasture on concentrations of conjugated linoleic acid in milk of lactating cows. J Dairy Sci 81:1630-1636

32. Coppa M, Ferlay A, Chassing C, Agabriel C, Glasser F, Chilliard $\mathrm{Y}$ et al (2013) Prediction of bulk milk fatty acid composition based on farming practices collected through on-farm surveys. J Dairy Sci 96:4197-4211

33. Collomb M, Schmid A, Sieber R, Wechsler D, Ryhänen E-L (2006) Conjugated linoleic acids in milk fat: variation and physiological effects. Int Dairy J 16:1347-1361

34. Couvreur S, Hurtaud C, Lopez C, Delaby L, Peyraud JL (2006) The linear relationship between the proportion of fresh grass in the cow diet, milk fatty acid composition, and butter properties. J Dairy Sci 89:1956-1969
35. Coppa M, Chassaing C, Ferlay A, Agabriel C, Laurent C, Borreani $\mathrm{G}$ et al (2015) Potential of milk fatty acid composition to predict diet composition and authenticate feeding systems and altitude origin of European bulk milk. J Dairy Sci 98:1539-1551

36. Velik M, Breitfuss S, Urdl M, Kaufmann J (2014) Fettsäurenmuster von Alm-, Vollweide- und Supermarkt-Milch sowie von Milch aus Heu-. Züchtungskunde 86:237-248

37. Parodi PW (2009) Has the association between saturated fatty acids, serum cholesterol and coronary heart disease been over emphasized? Int Dairy J 19:345-361

38. Buccioni A, Antongiovanni M, Petacchi F, Mele M, Serra A, Secchiari P et al (2008) Effect of dried or green herbage on vaccenic acid and conjugated linoleic acid production during in vitro rumen fermentation. Anim Feed Sci Technol 140:207-213 